\title{
Invasive and non-invasive congeneric Centaurea (Asteraceae) show contrasting patterns of herbivory by snails
}

\author{
João C. Filipe ${ }^{1, *}$, Andreia Jorge1, Özkan Eren², Gastón Sotes ${ }^{3,4}$, José Hierro ${ }^{5}$ \& Daniel Montesinos ${ }^{1}$
}

${ }^{1}$ Centre for Functional Ecology, Department of Life Sciences, University of Coimbra, Calçada Martim de Freitas, PT-3000-456 Coimbra, Portugal

${ }^{2}$ Adnan Menderes Üniversitesi, Fen-Edebiyat Fakültesi, Biyoloji Bölümü, Botanik Ana Bilim Dali, Aydin, Turkey

${ }^{3}$ Departamento de Botánica, Facultad de Ciencias Naturales y Oceanográficas, Universidad de Concepción, Víctor Lamas 1290, P.O. Box 160 C, Concepción, Chile

${ }^{4}$ Instituto de Ecología y Biodiversidad (IEB), Universidad de Chile, P.O. Box 653, Santiago, Chile

${ }^{5}$ INCITAP-CONICET and Facultad de Ciencias Exactas y Naturales, Universidad Nacional de La Pampa, AR-6300 Santa Rosa, Argentina

*Author for correspondence: filipe.j.carlos@gmail.com

\begin{abstract}
Background and aims - Once introduced into new regions, exotic species often experience shifts in resource allocation in response to the different environmental conditions found in the introduction range. Plants naturally respond to specialist herbivores with quantitative defences, by producing large amounts of toxic and non-toxic compounds that typically difficult digestion (e.g. tannins, cellulose), and to generalist herbivores with qualitative defences, like specialized noxious chemicals (e.g. alkaloids). The Shifting Defence Hypothesis $(\mathrm{SDH})$ poses that invasive plants decrease the production of defences against specialist herbivores in their introduction range, where specialist herbivores are usually absent, while boosting the production of defences against generalist herbivores.

Methods - We empirically assessed the response of a generalist herbivore, the common garden snail (Helix aspersa), to feeding with leaves of the annual herb Centaurea sulphurea, native to Europe and naturalized in North America; and the congeneric species $C$. solstitialis, which is also native to Europe and invasive in the Americas.

Key results - Snails fed with leaves from Spanish native populations the non-invasive $C$. sulphurea grew significantly less compared to snails fed with leaves from non-native California. For snails fed with the invasive $C$. solstitialis significant differences were also found among regions, but the response was more complex, depending on population, with snails fed with Turkish and Australian plants presenting higher growth rates than the rest of the regions.

Conclusions - Overall, our results stressed the importance of colonization history in shaping adaptive responses, and the stochasticity associated with colonization events of two closely related species, with contrasting invasive success and responses to herbivory.
\end{abstract}

Key words - Herbivory, chemical defences, invasive species, Centaurea.

\section{INTRODUCTION}

Plants are at the base of most terrestrial food webs, and herbivorous organisms play an important role in the consumption of the total vegetal biomass produced annually worldwide (Carmona et al. 2011). Plant-herbivore interactions often result in the development of diverse herbivore defence traits in plants in order to reduce the damage and impact produced by herbivory, and at the same time herbivores can evolve to respond to plant defences in an "arms race" (Berenbaum \& Feeny 1981). Plant defences can be chemical (sec- ondary metabolites; e.g. terpenoids, glucosinolates, tannins) and physical (e.g. latex, trichomes) (Ehrlich \& Raven 1964). Defensive traits can also be classified according to how they act as either qualitative or quantitative (Müller-Schärer et al. 2004). Quantitative defences are meant to provide resistance against specialist herbivores, and are based on digestibility reducers from the primary (e.g. cellulose) or secondary plant metabolism (e.g. tannins) that typically occur at high concentrations inside plant tissues. Qualitative defences are aimed against generalist herbivores, and include secondary plant metabolites with poisonous effects even at low concen- 
trations (e.g. sesquiterpene lactones; Müller-Schärer et al. 2004). Although secondary metabolites have been reported as important assets to defend plants from herbivores, a recent meta-analysis (Carmona et al. 2011) suggests that their importance for such trait is comparatively smaller than expected with other traits, such as genetic variation in life-history traits, leaf and stem morphology, and primary chemistry and physiology.

The success of some exotic species may be the result of a broad range of ecological and evolutionary factors, such as escape from enemies which are not present in non-native ranges (Keane \& Crawley 2002). In their native ranges, exotic plants are the target of highly kinds of herbivores with whom they share a complex evolutionary history, (Schaffner et al. 2011). However, in their non-native ranges, these plants are released of specialist herbivores but they can still be attacked by native generalist herbivores (Memmott et al. 2000). In this context, the Shifting Defence Hypothesis (SDH hereafter) proposes that, in their non-native range, exotic plants should reduce resource investments into specialized defences while increasing investments in defences aimed to generalist herbivores (Joshi \& Vrieling 2005).

A recent study evaluated epicuticular morphological and chemical defences of invasive Centaurea solstitialis L. leaves from native and non-native ranges (Sotes et al. 2015). The results showed an important production of sesquiterpene lactones, an important toxin with known activity against generalist herbivores (Amorim et al. 2013), that gradually increased in C. solstitialis' non-native regions (Sotes et al. 2015). Other preceding works with Centaurea invasive species had also suggested that sesquiterpene lactones could play a significant role in their success in their non-native regions (Kelsey \& Locken 1987, Stevens et al. 1990, Landau et al. 1994). In order to experimentally assess for potential differences in SDH patterns we fed generalist herbivore Helix aspersa Müller, 1,774 snails with leaves from the invasive $C$. solstitialis, and also with leaves of the exotic but non-invasive C. sulphurea Lag. Plants were grown in a common garden from seed originating from native and no-native regions of each species and we assessed how these potential defensive trait shifts affected the growth and survival of a generalist herbivore present across those same regions. Specifically, we wanted to assess if snail growth and survival was related to: (1) the region origin of the leaves with which they were fed; (2) the species of the Centaurea plants used to feed them, and (3) the invasive success of each of the Centaurea species.

\section{MATERIAL AND METHODS}

\section{Study species}

Centaurea solstitialis L. is an annual herb native to Southern Europe and Turkey which was introduced into California since at least 1824 and where it has become an aggressive invader (Maddox et al. 1985). Centaurea sulphurea Lag. is an annual herb native to Southern Europe and northern Africa and it was also introduced into California (USA) since at least 1923 (Muth \& Pigliucci 2006). Centaurea solstitialis occurs over broad native (Southern Europe) and non-native ranges (Americas and Australia), whereas C. sulphurea has a highly restricted native range in Spain and Morocco, and occurs at only a few populations in California (Gerlach \& Rice 2003). Both species inhabit the same ruderal habitats, and develop single bolting flower stems from basal rosettes. Both species form large spines on their capitula, providing a common trait for which to compare allocation to defence. (García at al. 2013).

Helix aspersa Müller, 1774 is a generalist herbivore snail native to the Mediterranean region and western Europe, from northwest Africa and Iberia eastwards to Asia Minor, and northwards to the British islands. H. aspersa has been spread by humans, either deliberately or accidentally, and became naturalized in many regions with non-Mediterranean climates. It is present in Australia, New Zealand, and North and South America. It feeds on a variety of leaves, including a broad range of wild and domesticated plants (Pfleger \& Chatfield 1983).

\section{Experimental design}

For C. sulphurea, we used seeds collected in 2009 from seven different individuals from each of four different populations in Spain and three different populations in California (USA). For $C$. solstitialis, we used up to seven different individuals from each of 48 different populations sampled among six different regions (Turkey, Spain, Chile, Argentina, USA and Australia; see electronic appendix). For H. aspersa, we collected snails from the same cohort from a commercial snail farm. Snails had been grown in the same farm for more than ten generations, and were regularly fed with flour for snails, thus preventing the used snails from being pre-adapted to any specific Centaurea seed origin.

In February 2013, seeds from each population were germinated and grown in $2.2 \mathrm{~L}$ pots with a $30: 70 \mathrm{mix}$ of grit sand and farm soil and watered as needed. Plants were grown in common garden greenhouse conditions in Coimbra, Portugal, and the experiment started when all of them had grown at least ten leaves.

Snails were provided by the commercial snail farm Casa às Costas (Coimbra, Portugal), where a cohort of eight weeks old snails of similar size (young adults) was selected for the experiment. Prior to the start of the experiment, snails' total biomass was determined to the nearest milligram in a laboratory scale, measurements were repeated weekly and the experiments finished after four weeks for C. solstitialis, and two weeks for $C$. sulphurea. The difference in experimental times were due to differences in the leaf-phenology of the two Centaurea species. Snails were put in transparent $0.3 \mathrm{~L}$ plastic flasks with the opening covered with a mesh fixed to the flask with an elastic rubber band and placed in a randomized design onto a table in laboratory conditions, i.e. at ambient temperature and light conditions. Feeding was made by dropping half a leaf inside each flask every other day. After every feeding, fresh water was also sprayed inside of the flask in order to keep the humidity levels stable so the snails would not estivate due to dry conditions. Snails were fed ad libitum for the duration of the experiment, and each snail was always fed with leaves from the same individual plant. Since snails always had abundant fresh leaves to eat, potential differences in snail's growth would be more parsimoniously explained by 
differences in leaf herbivory defences that by differences in leaf nutrient content.

\section{Statistical analyses}

Growth rates were calculated as the absolute difference between final and initial snail biomass, divided by the number of days. Data from both plant study species was analysed with R 3.2.2 (R Core Team 2015). Growth rate (GR) was based on absolute values and analysed by means of linearmixed effects models (procedure "lme") with region as a fixed factor, population within region as a random factor and GR as the study variable. Data was log-transformed for homoscedasticity. When necessary, Tukey's post-hoc was run (procedure "multcomp").

\section{RESULTS}

Snails fed with leaves of $C$. sulphurea of Californian origin presented GR values more than $80 \%$ higher than those fed with leaves of Spanish origin $\left(\mathrm{L}^{\mathrm{R}} \mathrm{Ratio}_{3,4}=7.040\right.$; $\operatorname{logLik}=$
-17.507; $p=0.008)$. The random factor "population" presented standard deviations (SD) and residuals nearing zero, thus indicating that its importance in structuring the data was likely low $\left(\mathrm{SD}=3.290\right.$ 10 $0^{-7}$; Residual = 0.008) $($ fig. 1).

For $C$. solstitialis we did find significantly different GRs among some regions $\left(\right.$ L. Ratio $_{3,8}=18.880$; logLik $=639.913$; $\mathrm{p}=0.002$ ). The random factor "population" presented SD also nearing zero, and although it presented slightly higher residuals its importance in structuring the data was also likely low $\left(\mathrm{SD}=6.63510^{-6}\right.$; Residual $\left.=0.348\right)$. Post-hoc analyses showed that Turkish populations were significantly different $(\mathrm{p}<0.05)$ from every other region except for Australia $(\mathrm{z}=-0.453 ; \mathrm{p}=0.997)$ and marginally different from Chile $(z=-2.753 ; p=0.0615)$ (fig. 2$)$. Net mass gain for each treatment paralleled RGR results, and can be viewed in table 1 .

\section{DISCUSSION}

For the invasive plant species $C$. solstitialis, snails fed with leaves from Spain, Argentina, and California showed lower

Table 1 - Total biomass gain by snails for each Centaurea species by region.

The feeding with leaves from both $C$. solstitialis and C. sulphurea finished after 28 and 14 days respectively. Prior to the start of the experiment, a set of snails with similar size was selected and their total initial biomass was determined to the nearest milligram in a laboratory scale.

\begin{tabular}{cccc}
\hline Species & Region & Mean biomass gain $(\mathrm{g})$ & SE \\
\hline \multirow{3}{*}{ Centaurea solstitialis } & Turkey & 0.170 & 0.039 \\
& Spain & 0.095 & 0.025 \\
& Chile & 0.118 & 0.039 \\
& Argentina & 0.130 & 0.018 \\
& California & 0.094 & 0.011 \\
& Australia & 0.174 & 0.070 \\
\hline \multirow{2}{*}{ Centaurea sulphurea } & Spain & 0.158 & 0.027 \\
& California & 0.283 & 0.044 \\
\hline
\end{tabular}

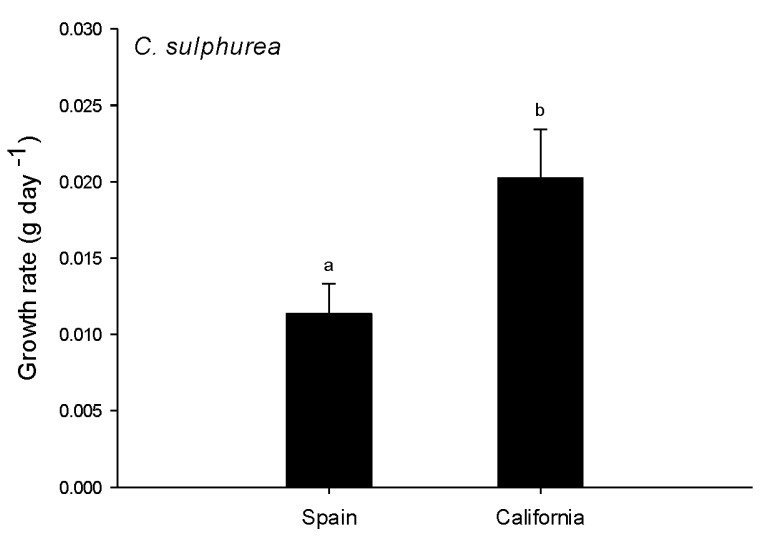

Figure 1 - Helix aspersa growth rate based on absolute mass gains per day ( $\mathrm{g}$; mean $\pm \mathrm{SE}$ ) when fed with Centaurea sulphurea leaves from plants from each region, native (Spain) and non-native (California). Means with different letters are significantly different $(\mathrm{p} \leq 0.05)$.

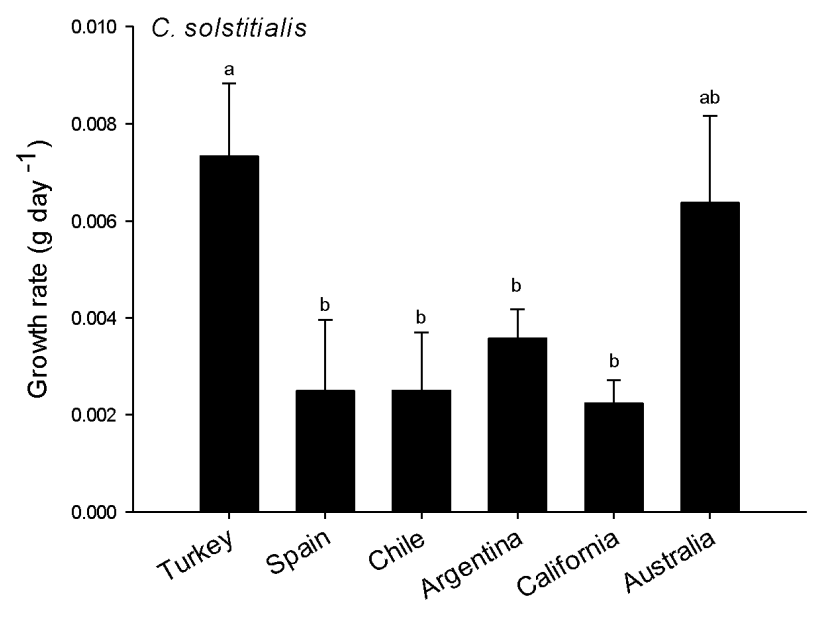

Figure 2 - Helix aspersa growth rate based on absolute mass gains per day (g; mean $\pm \mathrm{SE}$ ) when fed with Centaurea solstitialis leaves from plants from each region, native (Turkey, Spain) and non-native (Chile, Argentina, California and Australia). Means with different letters are significantly different $(\mathrm{p} \leq 0.05)$. 
growth rates than those fed with leaves from Turkey or Australia, with Chile showing intermediate values between the two groups. This suggests that plants from Spain, Argentina and California could be investing more resources into defence against generalist herbivores than plants from Turkey and Australia. These results partially support the SDH hypothesis, and in agreement with previous chemical studies showing increasing amounts of sesquiterpene lactones from Turkey (53\%), to Spain (69\%), Chile (72\%), and California (75\%) (Sotes et al. 2015); in a coherent inverse trend with the growth rate values found on this study for snails fed with C. solstitialis leaves, in which higher reported concentrations of sesquiterpene lactones correspond to lower snail growth rates. The results were also consistent with previous genetic studies describing the migration route of the species. Initially, C. solstitialis spread with the expansion of agriculture from Turkey through the Mediterranean to Spain. Later, it was recently introduced into Argentina, Chile and California (Eriksen et al. 2014). In this context, is thus interesting to ponder the similarity between the values found for Turkey and Australia, which point towards a potential Turkish origin of seeds invading Australia, although genetic data for Australian populations is currently missing.

Interestingly, snails fed with leaves from the non-native range of the non-invasive $C$. sulphurea presented higher growth rates than snails fed with leaves from the native Spain, i.e. exactly the opposite to what was found for C. solstitialis, suggesting that different trait-shifts in herbivory defence might be involved in the different invasive success of each species in California, where C. sulphurea might be more vulnerable to generalist herbivores.

Inter-regional trait-shifts among plants from native and non-native regions, such are the ones presented here, typically include traits like higher germination rates, reproductive outputs, and size (Ridenour et al. 2008, Jakobs et al. 2004). Some of these traits could be the result of resource trade-offs with either generalist or specialist herbivore defences (Willis et al. 1999, Maron et al. 2004), which could be interpreted as an evolutionary trade-off in the context of the hypothesis of Evolution of Increased Competitive Ability, EICA (Blossey \& Notzold 1995). Our results indicate that herbivory and herbivory defence might underlie the contrasting invasive success of these two species, although a recent meta-analysis suggests that in fact secondary metabolites might play secondary role for the anti-herbivore defence of plants when compared with other traits (Carmona et al. 2011).

In conclusion, our results are partially supportive of the Shifting Defence Hypothesis (SDH), with the invasive species $C$. solstitialis showing a tendency towards reducing growth of generalist herbivores in its American non-native range, and the non-invasive C. sulphurea showing the opposite pattern. However, further studies are needed to confirm this pattern, and to test it with other herbivores (e.g. aphids). In any case, these results should be interpreted with caution, since some trait-shifts are known to occur both in invasive and non-invasive species, and might not be necessarily responsible for invasive success, which could be better explained by a complex combination of traits (García et al. 2013).

\section{SUPPLEMENTARY DATA}

Supplementary data are available in pdf at Plant Ecology and Evolution, Supplementary Data Site (http://www.ingentaconnect.com/content/botbel/plecevo/supp-data), and consist of a table retracing origin of Centaurea seeds used in the study.

\section{ACKNOWLEDGEMENTS}

Research was funded by the Portuguese Fundação para a Ciência e a Tecnologia - FCT (PCT/BIA-PLA/3389/2012). DM was funded by FCT (IF-00066-2013), and by the European Commission (FP7-PEOPLE-MC-CIG-321909). FCT is partially funded by the European Union via QREN, COMPETE and FEDER. The authors wish to thank the staff, colleagues, and friends at CFE-UC for their support.

\section{REFERENCES}

Amorim M.H.R., Gil da Costa R.M., Lopes C., Bastos M.M.S.M. (2013) Sesquiterpene lactones: adverse health effects and toxicity mechanisms. Critical Reviews in Toxicology 43: 559-579. http://dx.doi.org/10.3109/10408444.2013.813905

Berenbaum M., Feeny P. (1981) Toxicity of angular furanocoumarins to swallowtail butterflies: escalation in a coevolutionary arms race? Science 212: 927-929. http://dx.doi.org/10.1126/ science.212.4497.927

Blossey B., Notzold R. (1995) Evolution of increased competitive ability in invasive nonindigenous plants: a hypothesis. Journal of Ecology 83: 887-889. http://dx.doi.org/ 10.2307/2261425

Carmona D., Lajeunesse M.J., Johnson M.T.J. (2011) Plant traits that predict resistance to herbivores. Functional Ecology 25: 358-367. http://dx.doi.org/10.1111/j.1365-2435.2010.01794.x

Ehrlich P.R., Raven P.H. (1964) Butterflies and plants: a study in coevolution. Evolution 18: 586-608. http://dx.doi. org/10.2307/2406212

Eriksen R.L., Hierro J.L., Eren Ö., Andonian K., Török K., Becerra P.I., Montesinos D., Khetsuriani L., Diaconu A., Kesseli R. (2014) Dispersal pathways and genetic differentiation among worldwide populations of the invasive weed Centaurea solstitialis L. (Asteraceae). PLoS ONE 9: e114786. http://dx.doi. org/10.1371/journal.pone.0114786

García Y., Callaway R.M., Diaconu A., Montesinos D. (2013) Invasive and non-invasive congeners show similar trait shifts between their same native and non-native ranges. PLoS ONE 8: e82281. http://dx.doi.org/10.1371/journal.pone.0082281

Gerlach J.D. Jr., Rice K.J. (2003) Testing life history correlates of invasiveness using congeneric plant species. Ecological Applications 13: 167-179. http://dx.doi.org/10.1890/10510761(2003)013[0167:TLHCOI]2.0.CO;2

Jakobs G., Weber E., Edwards P.J. (2004) Introduced plants of the invasive Solidago gigantea (Asteraceae) are larger and grow denser than conspecifics in the native range. Diversity and Distributions 10: 11-19. http://dx.doi.org/10.1111/j.14724642.2004.00052.x

Joshi J., Vrieling K. (2005) The enemy release and EICA hypothesis revisited: incorporating the fundamental difference between specialist and generalist herbivores. Ecology Letters 8: 704-714. http://dx.doi.org/10.1111/j.1461-0248.2005.00769.x

Keane R.M., Crawley M.J. (2002) Exotic plant invasions and the enemy release hypothesis. Trends in Ecology \& Evolution 17: 164-170. http://dx.doi.org/10.1016/S0169-5347(02)02499-0 
Kelsey R.G., Locken L.J. (1987) Phytotoxic properties of cnicin, a sesquiterpene lactone from Centaurea maculosa (spotted knapweed). Journal of Chemical Ecology 13: 19-33. http://dx.doi. org/10.1007/BF01020348

Landau I., Müller-Schärer H., Ward P.I. (1994) Influence of cnicin, a sesquiterpene lactone of Centaurea maculosa (Asteraceae), on specialist and generalist insect herbivores. Journal of Chemical Ecology 20: 929-942. http://dx.doi.org/10.1007/BF02059588

Maddox D.M., Mayfield A., Poritz N.H. (1985) Distribution of yellow starthistle (Centaurea solstitialis) and russian knapweed (Centaurea repens). Weed Science 33: 315-327.

Maron J.L., Vilà M., Arnason J. (2004) Loss of enemy resistance among introduced populations of St. John's wort (Hypericum perforatum). Ecology 85: 3243-3253. http://dx.doi. org/10.1890/04-0297

Memmott J., Fowler S.V., Paynter Q.A., Sheppard A.W., Syrett P. (2000) The invertebrate fauna on broom, Cytisus scoparius, in two native and two exotic habitats. Acta Oecologica 21: 213 222. http://dx.doi.org/10.1016/S1146-609X(00)00124-7

Müller-Schärer H., Schaffner U., Steinger T. (2004) Evolution in invasive plants: implications for biological control. Trends in Ecology \& Evolution 19: 417-422. http://dx.doi.org/10.1016/j. tree.2004.05.010

Muth N.Z., Pigliucci M. (2006) Traits of invasives reconsidered: phenotypic comparisons of introduced invasive and introduced noninvasive plant species within two closely related clades. American Journal of Botany 93: 188-196. http://dx.doi. org/10.3732/ajb.93.2.188

Pfleger V., Chatfield J. (1988) A guide to snails of Britain and Europe. London, Hamlyn.

R Core Team (2015) R: a language and environment for statistical computing. Vienna, R Foundation for Statistical Comput- ing. Available at https://www.R-project.org/ [accessed 24 Mar. 2016].

Ridenour W.M., Vivanco J.M., Feng Y., Horiuchi J.I., Callaway R.M. (2008) No evidence for trade-offs: Centaurea plants from America are better competitors and defenders. Ecological Monographs 78: 369-386. http://dx.doi.org/10.1890/06-1926.1

Schaffner U., Ridenour W.M., Wolf V.C., Bassett T., Müller C., Müller-Schärer H., Sutherland S., Lortie C.J., Callaway R.M. (2011) Plant invasions, generalist herbivores, and novel defence. Ecology 92: 829-835. http://dx.doi.org/10.1890/101230.1

Sotes G.J., Cavieres L.A., Montesinos D., Pereira Coutinho A.X., Peláez W.J., Lopes S.M.M., Pinho e Melo T.M.V.D. (2015) Inter-regional variation on leaf surface defenses in native and non-native Centaurea solstitialis plants. Biochemical Systematics and Ecology 62: 208-218. http://dx.doi.org/10.1016/j. bse.2015.09.003

Stevens K.L., Riopelle R.J., Wong R.Y. (1990) Repin, a sesquiterpene lactone from Acroptilon repens possessing exceptional biological activity. Journal of Natural Products 53: 218-221. http://dx.doi.org/10.1021/np50067a038

Willis A.J., Thomas M.B., Lawton J.H. (1999) Is the increased vigour of invasive weeds explained by a trade-off between growth and herbivore resistance? Oecologia 120: 632-640. http:// dx.doi.org/10.1007/s004420050899

Manuscript received 26 Feb. 2016; accepted in revised version 24 Mar. 2016.

Communicating Editor: Pierre Meerts. 